\title{
Astragaloside IV suppresses inflammatory mediator production in synoviocytes and collagen-induced arthritic rats
}

\author{
HAO XU, CHANG-YAO WANG, HAI-NING ZHANG, CHENG-YU LV and YING-ZHEN WANG \\ Joint Department of Affiliated Hospital of Qingdao University, Qingdao University, \\ Qingdao, Shandong 266100, P.R. China
}

Received May 15, 2015; Accepted January 14, 2016

DOI: $10.3892 / \mathrm{mmr} .2016 .4923$

\begin{abstract}
The aim of the current study was to investigate the effects of Astragaloside-IV (AS-IV) on inflammatory mediators in synoviocytes and collagen-induced arthritic rats. Synoviocytes were stimulated with lipopolysaccharides (LPS) and Sprague-Dawley rats were injected with type II collagen. AS-IV was administered to the LPS-stimulated synoviocytes and collagen-induced arthritis (CIA) rats. The inflammation of LPS-stimulated synoviocytes and CIA rats was assessed using enzyme-linked immunosorbent assays and western blotting. Using Cell Counting Kit-8 analysis, it was demonstrated that $\operatorname{AS}-I V(5,20$ and $50 \mathrm{mg} / \mathrm{ml})$ inhibited the LPS-stimulated synoviocytes proliferation in a dose-dependent manner. AS-IV significantly inhibited the LPS-stimulated inflammatory response, as indicated by the expression levels of TNF- $\alpha$, IL-1 $\beta$, IL-6 and IL-8. In addition, treatment with AS-IV significantly reduced the LPS-stimulated cyclooxygenase (COX)-1, COX-2, high mobility group box 1 protein (HMGB1) and intercellular adhesion molecule 1 overexpression, and intranuclear nuclear factor (NF)- $\mathrm{Bp} 65$ subunit accumulation and activation of c-Jun N-terminal kinase (JNK)1/2 and p38. Similar to the protective effects of AS-IV on LPS-stimulated synoviocytes, AS-IV treatment significantly reduced the expression levels of tumor necrosis factor $\alpha$, interleukin (IL)-1 $\beta$, IL-6 and IL-8 expression levels, and attenuated intranuclear NF- $\kappa$ B 65 subunit accumulation and overexpression of COX-2 and inducible nitric oxide synthase in CIA rats. In conclusion, the results of the present study demonstrated for the first time, to the best of our knowledge, that AS-IV protects synoviocytes against LPS- and collagen-induced inflammatory responses through inhibition of the HMGB1-dependent JNK1/2- and p38-activated NF- $\mathrm{BB} / \mathrm{COX}-2$ pathway.
\end{abstract}

Correspondence to: Professor Ying-Zhen Wang, Joint Department of Affiliated Hospital of Qingdao University, Qingdao University, 59 Haier Road, Laoshan, Qingdao, Shandong 266100, P.R. China E-mail: xyz1102@hotmail.com

Key words: astragaloside IV, synoviocyte, arthritis, immunology

\section{Introduction}

Rheumatoid arthritis (RA) is a chronic auto-immune inflammatory disease resulting in an inflammatory response in the synovium and injuries in cartilage and bone $(1,2)$. Nuclear factor $(\mathrm{NF})-\mathrm{\kappa B}$, a transcription factor, is a crucial regulator of inflammation in RA (3). NF- $\mathrm{kB}$ controls the expression levels of the pro-inflammatory cytokines, including interleukin $1 \beta$ (IL-1 $\beta$ ) and tumor necrosis factor $\alpha$ (TNF- $\alpha$ ), which are observed at a high expression level in the peripheral blood and synovial membrane (4). IL-1 $\beta$ and TNF- $\alpha$ cytokines are associated with the pathology of RA and induce the activation of NF- $\mathrm{KB}$, suggesting that the expression levels of IL- $1 \beta$ and TNF- $\alpha$ are regulated by NF- $\kappa B$ (5). Furthermore, $\mathrm{NF}-\mathrm{\kappa B}$ activation is necessary for the production of cyclooxygenase 2 (COX-2) and inducible nitric oxide synthase (iNOS), which catalyze the synthesis of prostanoids and nitric oxide metabolites (6).

Astragalus membranaceus Bge is a traditional Chinese tonic herb, widely used as a single herb or a collection of herbs in a complex prescription (7). Astragaloside IV (AS-IV), an active component purified from Astragalus membranaceus Bge $(8,9)$, serves a role in the regulation of numerous biological behaviors as a modulator of the immune system, and has been used in traditional Chinese medicine for many years to treat numerous diseases, such as Parkinson's disease, myocardial ischemia and RA (10-13). AS-IV suppresses joint inflammation in rat adjuvant-induced arthritis (AIA) via the inhibition of IL-1 $\beta$, TNF- $\alpha$ and iNOS production (14-16). However, the mechanism of this anti-inflammatory activity remains to be fully elucidated. Therefore, the mechanisms of AS-IV in the treatment of RA require further investigation in vivo or in vitro.

Collagen induced arthritis (CIA) is a chronic immune-inflammatory model used to elucidate the mechanism of RA pathogenicity and to evaluate anti-arthritic drugs $(17,18)$. A previous in vivo study demonstrated the effect of AS-IV on the splenocytes proliferation in AIA rats (16). Thus, in the present study, the cell proliferation Cell Counting Kit-8 (CCK-8), enzyme-linked immunosorbent assay (ELISA) and western blot assays were utilized to investigate whether or not AS-IV exerts an anti-inflammatory effect in the lipopolysaccharides (LPS)-stimulated synoviocytes and CIA rats. 


\section{Materials and methods}

Animals. All animal care and experimental procedures in the current study complied with the protocol approved by the Institutional Animal Care and Use Committee at Qingdao University (Shandong, China). A total of 30 male Sprague-Dawley rats (weight, 150-180 g; age, 8 weeks) were purchased from the Shanghai BK Experimental Animal Center (Shanghai, China). Rats were separated into cages $(n=5)$ and were fed laboratory feed and water, and were kept under a $12 \mathrm{~h}$ light/dark cycle at a constant temperature of $25^{\circ} \mathrm{C}$.

Cell culture. The synovial membrane was dissected from the underlying adipose subintima, transferred to Invitrogen Dulbecco's modified Eagle's medium (DMEM; Thermo Fisher Scientific, Inc., Waltham, MA, USA) containing $10 \%$ (v/v) heat-inactivated fetal calf serum (Gibco; Thermo Fisher Scientific, Inc.), $1 \%$ (v/v) penicillin $(5,000 \mathrm{U} / \mathrm{ml})$ and streptomycin $(5,000 \mu \mathrm{g} / \mathrm{ml})$ (Invitrogen; Thermo Fisher Scientific, Inc.), and immediately subjected to enzymatic digestion for $3 \mathrm{~h}$ at $37^{\circ} \mathrm{C}$. Newly released synoviocytes were seeded into $25 \mathrm{~cm}^{3}$ flasks. Subsequent to incubation for $48 \mathrm{~h}$, the medium was changed, removing any cells not adhered to the culture flask. Flasks were maintained by changing the medium at $48 \mathrm{~h}$ intervals until cell replication was observed; at that time, synoviocytes were seeded into 24 -well plates and grown to $80 \%$ confluence. Synoviocytes were incubated for $48 \mathrm{~h}$, using the following treatment conditions: Unstimulated (medium only); and LPS-stimulated (50 mg/ml; Sigma-Aldrich, St. Louis, MO, USA), LPS + AS-IV (5, 20 or $50 \mathrm{mg} / \mathrm{ml}$; Yuanmu Biotech Co., Ltd., Shanghai, China).

CCK-8 cell proliferation assay. Cell proliferation was assessed using the CCK-8 assay (Dojindo Molecular Technologies, Inc., Rockville, MD, USA) as previously described (19). Cells were plated at a density of $2 \times 10^{4}$ cells/well onto a 96 -well plate, treated with LPS in the presence or absence of AS-IV $(5,20$, and $50 \mathrm{mg} / \mathrm{ml})$ for $72 \mathrm{~h}$ and the cell proliferation was determined according to the manufacturer's instructions. Absorbance of the supernatant for each well was measured at $450 \mathrm{~nm}$ using the Multiskan EX plate reader (Thermo Fisher Scientific, Inc.).

Collagen-induced arthritis. Sprague-Dawley rats were immunized with $500 \mathrm{mg} / \mathrm{kg}$ of bovine type II collagen emulsified with an equal volume of complete Freund's adjuvant (Chondrex, Inc., Redmond, WA, USA) as previously described (20). Following immunization, arthritic rats were randomly divided into five groups ( $\mathrm{n}=6$ ), control rats, no treatment; LPS treatment; LPS treatment in the presence of three different concentrations of AS-IV $(5,20$ and $50 \mathrm{mg} / \mathrm{ml})$. To examine the therapeutic effect of AS-IV, arthritic rats were injected with 5 , 20 and $50 \mathrm{mg} / \mathrm{kg}$ AS-IV on days 27 and 30 . On day 45, the rats were anesthetized with $\mathrm{CO}_{2}$ and then a cervical dislocation was performed. Synovial tissues were harvested from each animal for ELISA and western blot analysis.

ELISA assay. The experimental procedure was performed using an ELISA kit (R\&D Systems, Inc., Minneapolis, MN, USA) according to the manufacturer's instructions.
LPS-stimulated synoviocytes $\left(2 \times 10^{5}\right.$ cells per 60 -mm dish per $2 \mathrm{ml}$ of serum-free media) and collagen-induced arthritic rats were treated with AS-IV for $24 \mathrm{~h}$. Cultured supernatants and serum were collected and subjected to ELISA for measurement of TNF- $\alpha$, IL-1 $\beta$, IL-6, IL-8, COX-1, COX-2, high mobility group box 1 protein (HMGB1) and intercellular adhesion molecule 1 (ICAM-1).

Western blot analysis. Western blotting was performed as previously described (21). LPS-stimulated synoviocytes and collagen-induced synovial tissues were serum-starved overnight and then treated with AS-IV for $24 \mathrm{~h}$. Cells were subjected to sodium dodecyl $10 \%$ sulfate-polyacrylimide gel (Sigma-Aldrich) electrophoresis using a Bio-Rad miniature slab gel apparatus (Bio-Rad Laboratories, Inc., Hercules, CA, USA) and proteins were electrophoretically transferred onto a nitrocellulose membrane (EMD Millipore, Billerica, MA, USA). Membranes were incubated with primary antibodies rabbit pAb against iNOS (cat. no. ab3523; 1:1,000; Abcam, Cambridge, MA, USA), Rabbit mAb against COX2 (cat. no. 12282; 1:1,000), c-Jun N-terminal kinase (JNK1/2; cat. no. 9252; 1:1,000), p38 (cat. no. 8690; 1:1,000), histone H3 (cat. no. 4499; 1:800), $\beta$-actin (cat. no. $4970 ; 1: 1,000$ ), and GAPDH (cat. no. 5174; 1:1,500), mouse mAb against p-JNK1/2 (cat. no. 9255; 1:1,000), p-p38 (cat. no. 9216; 1:800), and NF-кB p65 (cat. no. $6956 ; 1: 1,000$ ) overnight at $4^{\circ} \mathrm{C}, 9$ antibodies purchased from Cell Signaling Technology, Inc. (Danvers, MA, USA) . Membranes were washed and incubated with goat anti-rabbit and goat anti-mouse horseradish peroxidase-conjugated secondary antibodies (cat. nos. A0208 and A0216; 1:1,000; Beyotime Institute of Biotechnology, Haimen, China) for $1 \mathrm{~h}$ at $37^{\circ} \mathrm{C}$, and visualized with enhanced chemiluminescence (Merck Millipore, Beijing, China) according to the manufacturer's protocol.

Statistical analysis. Statistical analysis was performed using GraphPad Prism software, version 5.0 (GraphPad Software, Inc., La Jolla, CA, USA). Differences among groups were analyzed using Student's two-tailed t-test, and all statistical analyses were two-sided. $\mathrm{P}<0.05$ was considered to indicate a statistically significant difference.

\section{Results}

AS-IV inhibited the proliferation of LPS-stimulated synoviocytes. The chemical structure of AS-IV is presented in Fig. 1A. To determine the effect of AS-IV on the proliferation of synoviocytes with or without LPS induction, cell proliferation was determined. As demonstrated in Fig. 1B, LPS treatment resulted in a significant increase in the proliferation of synoviocytes compared with that of the untreated control $(\mathrm{P}<0.01)$. In the presence of LPS, administration of AS-IV (5, 20 or $50 \mathrm{mg} / \mathrm{ml}$ ) significantly inhibited synoviocyte proliferation in a dose- and time-dependent manner compared with the LPS-stimulated synoviocytes group (Fig. 1B; P<0.01).

AS-IV inhibited inflammatory mediator production by LPS-stimulated synoviocytes. IL- $1 \beta$, TNF- $\alpha$, IL- 6 and IL-8 expression levels in response to AS-IV and LPS were determined. Following stimulation of the synoviocytes with LPS, 
A

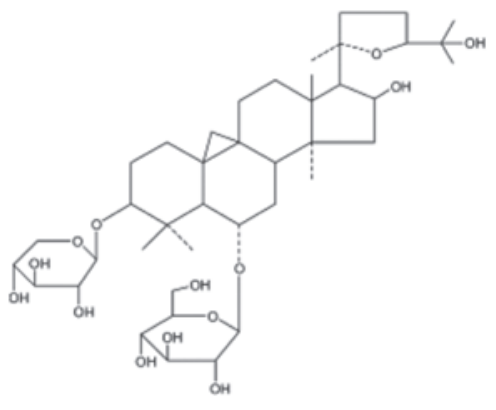

B

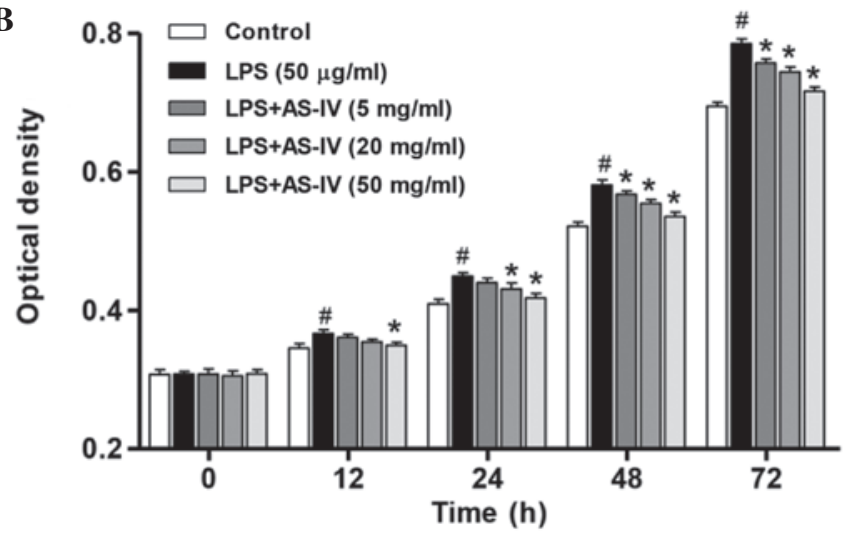

Figure 1. AS-IV inhibited the proliferation of LPS-stimulated synoviocytes. (A) Chemical structure of AS-IV. (B) Cell proliferation was determined following AS-IV treatment $(5,20$ and $50 \mathrm{mg} / \mathrm{ml})$ for $0,12,24,48$ and $72 \mathrm{~h}$. Data are presented as the mean \pm standard deviation $(\mathrm{n}=3) .{ }^{~} \mathrm{P}<0.01 \mathrm{vs}$. the untreated control synoviocytes. ${ }^{\text {P }}<0.01$ vs. the LPS-stimulated synoviocytes. LPS, lipopolysaccharide; AS-IV, astragaloside IV.

A

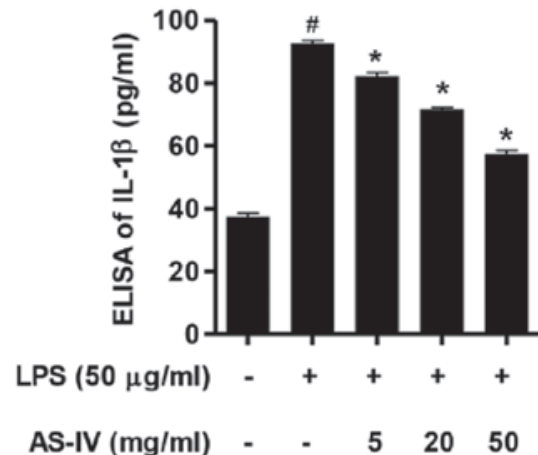

C

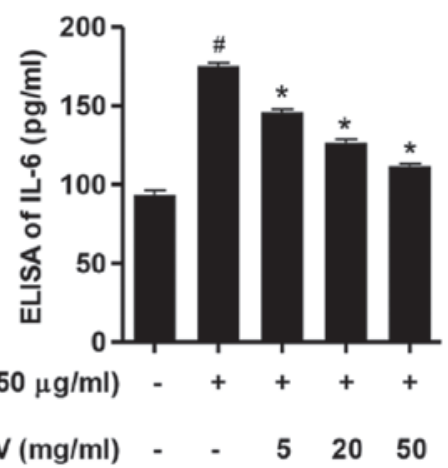

B

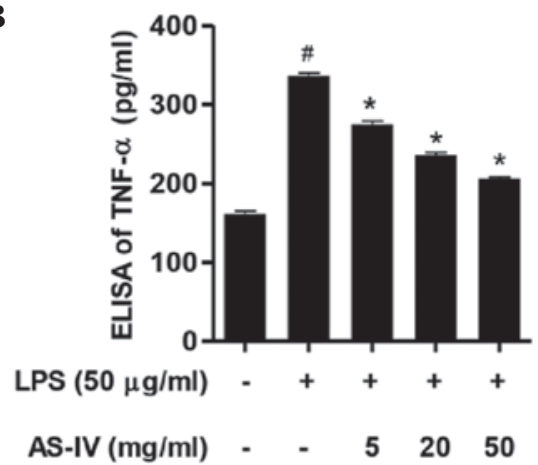

D

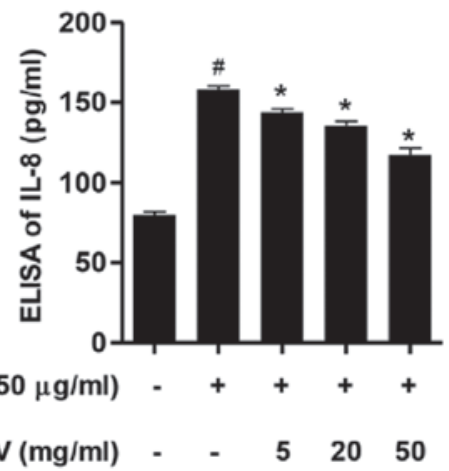

Figure 2. AS-IV inhibited IL-1 $\beta$, TNF- $\alpha$, IL-6 and IL-8 expression in LPS-stimulated synoviocytes. Synoviocytes were stimulated with LPS in the absence or presence of AS-IV treatment. ELISA analysis of (A) IL-1 $\beta$, (B) TNF- $\alpha$, (C) IL-6 and (D) IL- 8 expression levels in cell supernatants. Data are presented as the mean \pm standard deviation $(n=3)$. ${ }^{\#} \mathrm{P}<0.01$ vs. the untreated control synoviocytes and ${ }^{*} \mathrm{P}<0.01$ vs. the LPS-stimulated synoviocytes. ELISA, enzyme-linked immunosorbent assay; IL-1 $\beta$,interleukin $1 \beta$; LPS, lipopolysaccharide; AS-IV, astragaloside IV; TNF- $\alpha$, tumor necrosis factor $\alpha$.

the expression levels of IL-1 $\beta$, TNF- $\alpha$, IL- 6 and IL- 8 were significantly increased compared with the control group (Fig. 2; $\mathrm{P}<0.01)$. Further administration of $\mathrm{AS}-\mathrm{IV}(5,20$ or $50 \mathrm{mg} / \mathrm{ml})$ significantly inhibited the expression levels of IL- $1 \beta$, TNF- $\alpha$, IL-6 and IL-8 compared with the LPS-stimulated synoviocytes (Fig. 2; $\mathrm{P}<0.01$ ). These results indicate that AS-IV possesses an anti-inflammatory effect in LPS-stimulated synoviocytes.

Downregulation of COX-1/COX-2/HMGB1/ICAM-1 overexpression contributed to the cytoprotection of $A S-I V$ in LPS-stimulated synoviocytes. Following stimulation of the synoviocytes with LPS, the ELISA assay demonstrated that the expression levels of COX-1, COX-2, HMGB1 and ICAM-1 were significantly increased compared with the control group (Fig. 3; P<0.01). Further treatment with AS-IV (5, 20 or $50 \mathrm{mg} / \mathrm{ml}$ ) significantly attenuated the overexpression of COX-1, COX-2, HMGB1 and ICAM-1 compared with the LPS-stimulated synoviocytes (Fig. 3; P<0.01). These results demonstrate that COX-1, COX-2, HMGB1 and ICAM-1 mediate LPS-stimulated cytotoxicity and inflammatory responses, and that the inhibition of the LPS-stimulated COX-1, COX-2, HMGB1 and ICAM-1 overexpression is involved in the AS-IV-mediated protective effect in synoviocytes. 
A

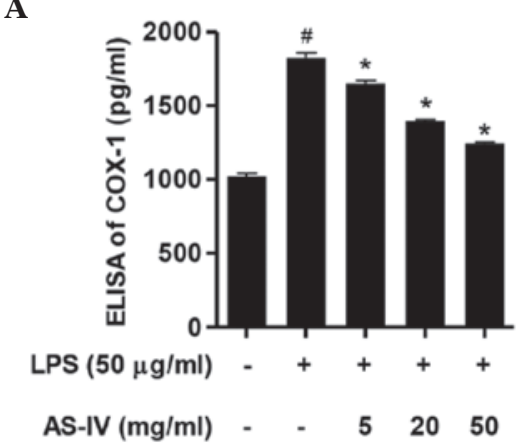

C

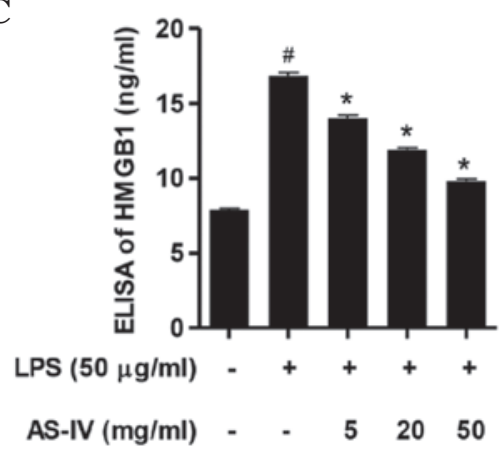

B

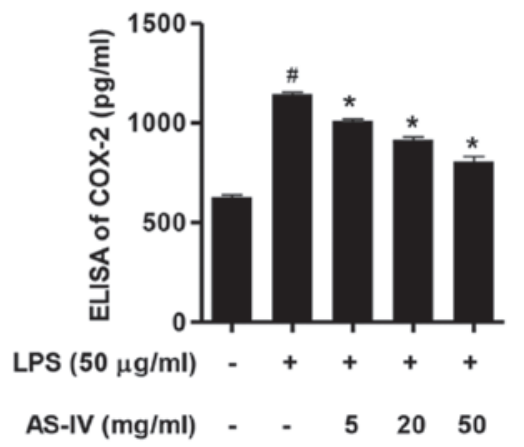

D

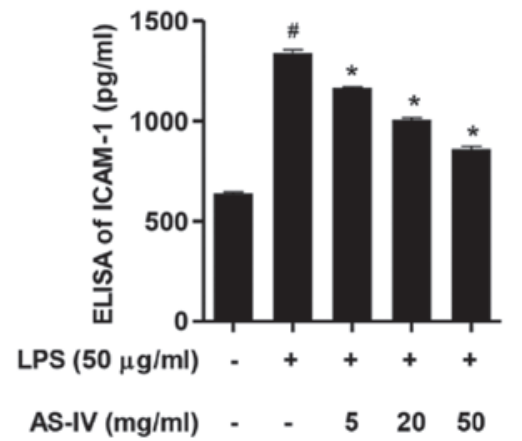

Figure 3. AS-IV inhibited the LPS-stimulated COX-1, COX-2, HMGB1 and ICAM-1 overexpression. Synoviocytes were stimulated with LPS in the absence or presence of AS-IV treatment. ELISA analysis of (A) COX-1, (B) COX-2, (C) HMGB1 and (D) ICAM-1 expression levels in cell supernatants. Data are presented as the mean \pm standard deviation $(\mathrm{n}=3) .{ }^{*} \mathrm{P}<0.01$ vs. the untreated control synoviocytes and ${ }^{*} \mathrm{P}<0.01$ vs. the LPS-stimulated synoviocytes. ELISA, enzyme-linked immunosorbent assay; COX-1, cyclooxygenase 1; LPS, lipopolysaccharide; AS-IV, astragaloside IV; HMGB1, high mobility group box 1; ICAM-1, intercellular adhesion molecule 1.

Inhibition of $N F-\kappa B, J N K 1 / 2$ and 38 activation was implicated in the cytoprotection of AS-IV in LPS-stimulated synoviocytes. To further clarify the mechanism underlying the in vitro protective effect of AS-IV, the NF- $\kappa \mathrm{B}$ signaling pathway was investigated in nuclear and cytoplasmic extracts, and the activity of JNK1/2 and p38 was also measured. Treatment of synoviocytes with LPS significantly enhanced the expression of the intranuclear NF- $\mathrm{kBp} 65$ subunit, an important step in NF- $\kappa \mathrm{B}$ activation, compared with the control group (Fig. 4A; $\mathrm{P}<0.0$ ). Furthermore, a significant reduction in the expression levels of the cytoplasmic NF- $\kappa$ Bp65 subunit expression compared with that of the untreated control synoviocytes was demonstrated (Fig. 4A; P $<0.01$ ), indicating that LPS stimulation may evoke NF- $\mathrm{kB}$ activation. Treatment of synoviocytes with AS-IV (5, 20 and $50 \mathrm{mg} / \mathrm{ml})$ significantly inhibited intranuclear NF- $\mathrm{KBp} 65$ subunit expression and enhanced the cytoplasmic NF- $\mathrm{kBp} 65$ subunit expression compared with the LPS-stimulated synoviocytes (Fig. 4A; P $<0.01$ ). In addition, treatment with AS-IV significantly reduced the LPS-stimulated COX-2 and iNOS overexpression compared with the LPS-stimulated synoviocytes (Fig. 4B, P<0.01).

The results from the ELISA assay demonstrated a significant overexpression of HMGB1 in the LPS-stimulated synoviocytes, thus the JNK1/2 and p38 signaling pathways activated by HMGB1 were investigated in the LPS-stimulated synoviocytes in the presence or absence of AS-IV. As demonstrated in Fig. 4C, the phosphorylation of JNK1/2 (p-JNK1/2) and p38 (p-p38) was significantly increased in the LPS-stimulated synoviocytes compared with the control group $(\mathrm{P}<0.01)$. Further treatment with AS-IV (5, 20 or $50 \mathrm{mg} / \mathrm{ml})$ significantly inhibited the activation of JNK $1 / 2$ and $\mathrm{p} 38$ compared with the LPS-stimulated synoviocytes (Fig. 4C, $\mathrm{P}<0.01$ ). The results suggest that the protection of AS-IV against inflammation and cytotoxicity resulted by LPS is partially associated with the inhibition of NF- $\mathrm{KB}, \mathrm{JNK} 1 / 2$ and $\mathrm{p} 38$ activation in synoviocytes.

Suppression of inflammatory mediator production and $N F-\kappa B$ activation involved in the pathophysiology of CIA by treatment with $A S-I V$. It is well known that inflammatory mediators serve key roles in the pathogenesis of RA (22). Therefore, the expression levels of inflammatory mediators obtained from the serum of rats on day 45 were assessed with the ELISA assay. Compared with the CIA rats, a significant reduction in IL-1 $\beta$, TNF- $\alpha$, IL- 6 and IL-8 expression levels was observed in the serum of AS-IV-treated rats (Fig. 5).

To further clarify the mechanism underlying the in vivo protective effect of AS-IV, the NF- $\mathrm{BB}$ signaling pathway was investigated in nuclear and cytoplasmic extracts. Treatment of rats with collagen significantly enhanced the intranuclear NF- $\mathrm{kBp} 65$ subunit expression and suppressed cytoplasmic NF-kBp65 subunit expression, compared with that of the untreated control rats (Fig. 6A; $\mathrm{P}<0.01$ ), indicating that collagen induction may evoke NF- $\kappa$ B activation. However, treatment of CIA rats with AS-IV $(5,20$ or $50 \mathrm{mg} / \mathrm{ml})$ significantly inhibited intranuclear NF- $\kappa$ Bp65 subunit expression and enhanced cytoplasmic NF-кBp65 subunit expression (Fig. 6A; P<0.01). Furthermore, treatment with AS-IV $(5,20$ and $50 \mathrm{mg} / \mathrm{ml})$ significantly reduced the collagen-induced COX-2 and iNOS overexpression compared with the collagen-induced arthritic 
A

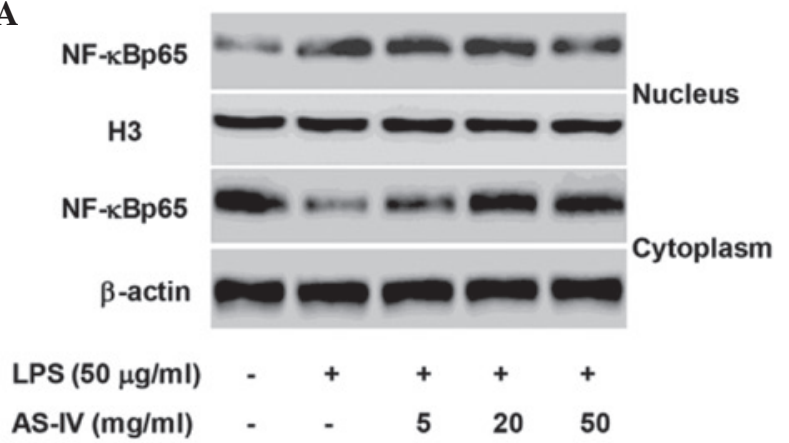

B

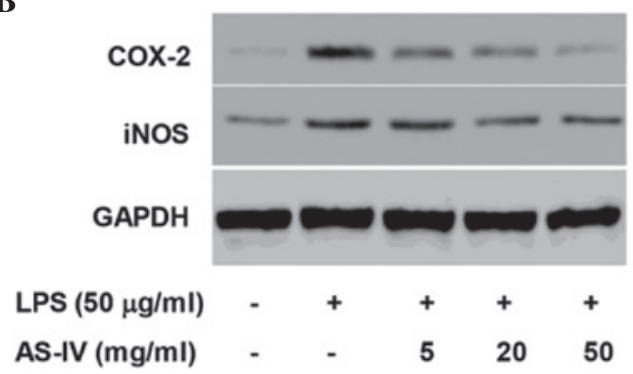

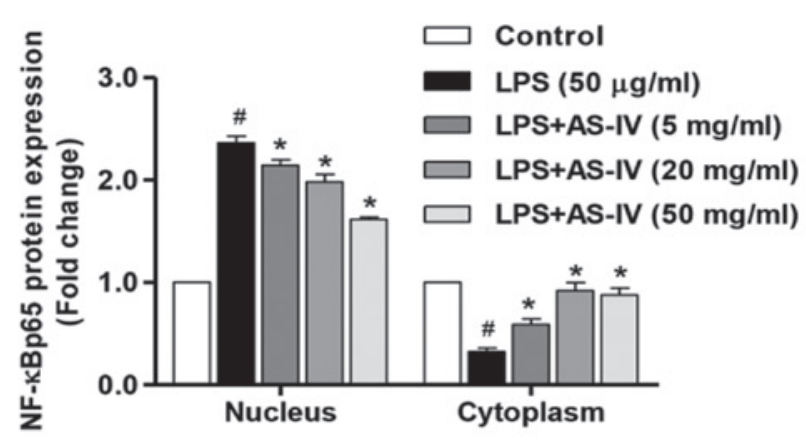
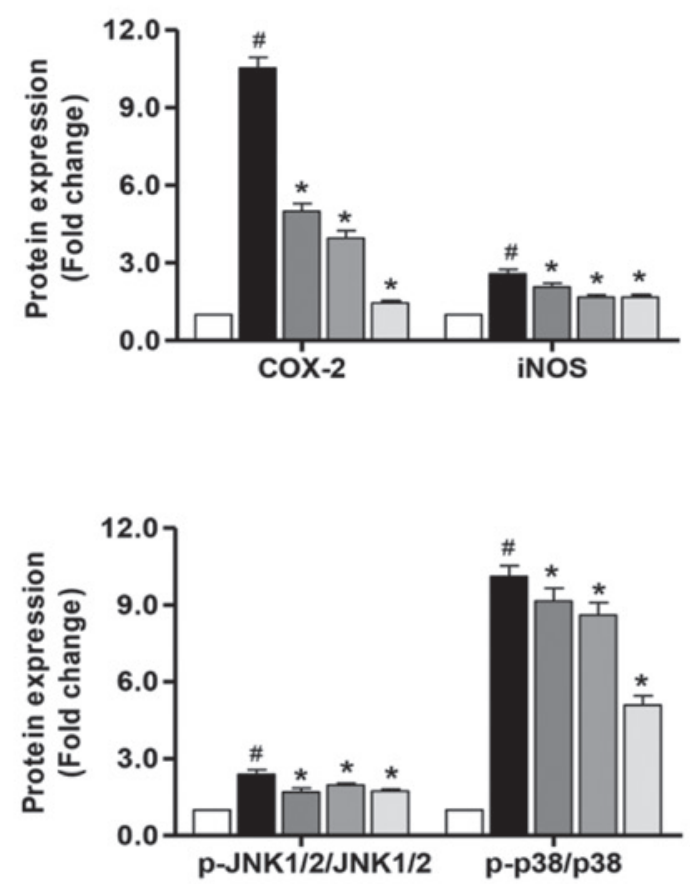

C

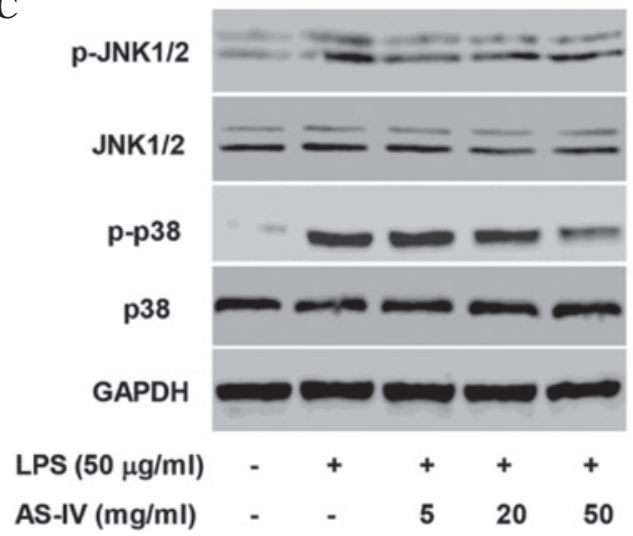

Figure 4. AS-IV inhibited the LPS-stimulated intranuclear accumulation of NF-kBp65 subunit and activation of JNK1/2 and p38 in synoviocytes. Synoviocytes were stimulated with LPS in the absence or presence of AS-IV treatment. (A) Nuclear and cytoplasmic extract lysates were subjected to western blot analysis and probed with the NF-кBp65 antibody. Cell lysates were subjected to western blot analysis and probed with (B) COX-2 and iNOS and (C) p-JNK1/2, JNK1/2, p-p38 and p38 antibodies. Data are presented as the mean \pm standard deviation $(n=3) .{ }^{~} \mathrm{P}<0.01$ vs. the untreated control synoviocytes and ${ }^{*} \mathrm{P}<0.01$ vs. the LPS-stimulated synoviocytes. NF-кBp65, nuclear factor кBp65; H3, histone 3; LPS, lipopolysaccharide; AS-IV, astragaloside IV; COX-2, cyclooxygenase 2; iNOS, inducible nitric oxide synthase; p-JNK1/2, phosphorylated-c-Jun N-terminal kinases 1/2.

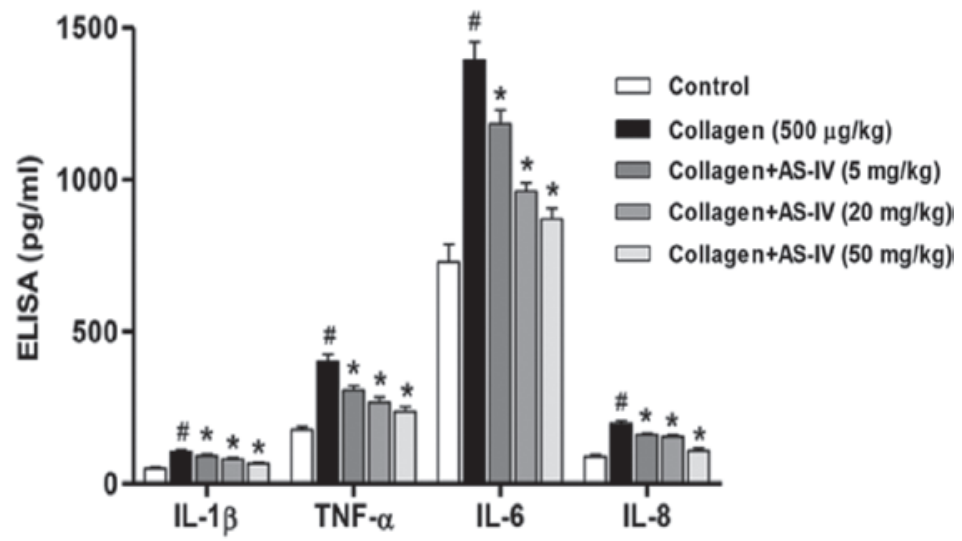

Figure 5. Effects of AS-IV on IL-1 $\beta$, TNF- $\alpha$, IL-6 and IL-8 expression in collagen-induced arthritic rats. Rats were induced by collagen in the absence or presence of AS-IV treatment. ELISA analysis of (A) IL-1 $\beta$, (B) TNF- $\alpha$, (C) IL-6 and (D) IL-8 expression levels in the serum. Data are presented as the mean \pm standard deviation $(\mathrm{n}=3) .{ }^{~} \mathrm{P}<0.01$ vs. the untreated control rats and ${ }^{~} \mathrm{P}<0.01 \mathrm{vs}$. the collagen-induced arthritic rats. ELISA, enzyme-linked immunosorbent assay; IL-1 $\beta$,interleukin $1 \beta$; LPS, lipopolysaccharide; AS-IV, astragaloside IV; TNF- $\alpha$, tumor necrosis factor $\alpha$. 
A

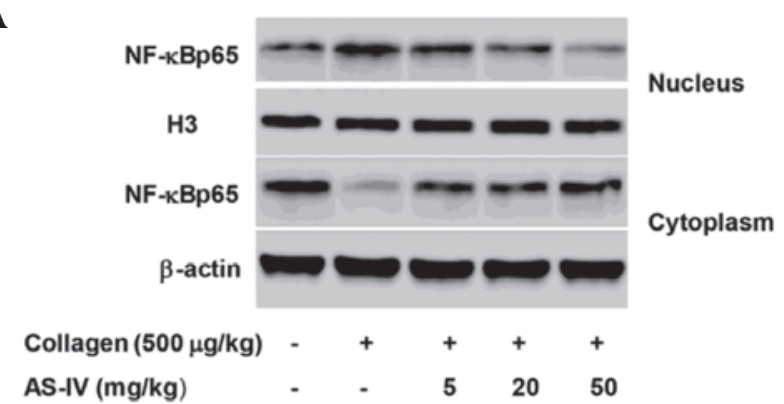

B

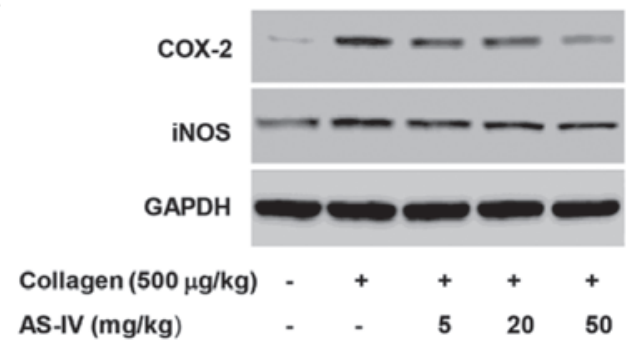

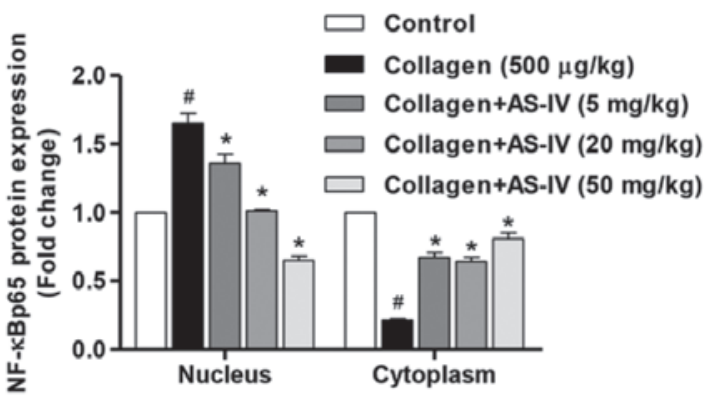

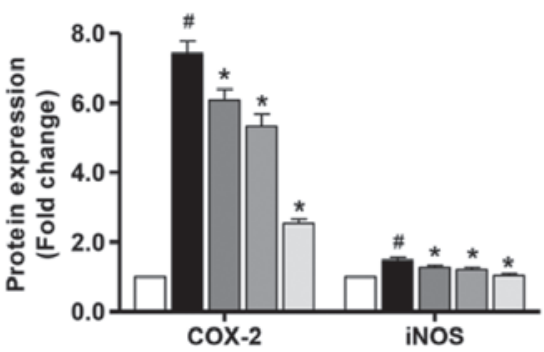

Figure 6. Effect of AS-IV treatment on the intranuclear accumulation of the NF- $\mathrm{Bp} 65$ subunit, and overexpression of COX-2 and iNOS in collagen-induced arthritic rats. Rats were induced by collagen in the absence or presence of AS-IV treatment. (A) Nuclear and cytoplasmic extract lysates were subjected to western blot analysis and probed with NF-кBp65 antibody. (B) Cell lysates were subjected to western blot analysis and probed with COX-2 and iNOS antibodies. Data are presented as the mean \pm standard deviation $(\mathrm{n}=3) .{ }^{\#} \mathrm{P}<0.01$ vs. the untreated control rats and ${ }^{*} \mathrm{P}<0.01$ vs. the collagen-induced arthritic rats NF-кBp65, nuclear factor $\kappa B p 65$; H3, histone 3; LPS, lipopolysaccharide; AS-IV, astragaloside IV; COX-2, cyclooxygenase 2; iNOS, inducible nitric oxide synthase.

rats (Fig. 6B; P0<0.01). These observations suggest that AS-IV induced a protective effect in rats with CIA through downregulating the synthesis of numerous inflammatory mediators and suppression of NF- $\mathrm{KB}$ activation.

\section{Discussion}

Anti-rheumatic drugs including methotrexate, celecoxib and TNF inhibitors have been used to reduce systemic inflammation. However, the efficacies of these agents are limited due to the side effects, such as vomiting and liver damage $(23,24)$. Thus, novel therapeutic agents with high efficiency and limited side effects are required for RA therapy.

The balance between pro-inflammatory mediators and anti-inflammatory mediators contributes to the development and progression of joint damage in RA (25). The present study investigated whether AS-IV exerts anti-inflammatory effects in synoviocytes. The cells were stimulated with LPS in the absence and presence of AS-IV, demonstrating that AS-IV inhibited the proliferation of synoviocytes in the presence of LPS in a dose- and time-dependent manner. The synoviocytes from patient with RA are pathological inflammatory cells independent of LPS treatment, thus the inhibitory effects of AS-IV on the inflammatory responses may not result from the cytotoxicity of AS-IV alone. In addition, administration of AS-IV significantly reduced the LPS-induced production of inflammatory mediators inducing IL- $1 \beta$, TNF- $\alpha$, IL- 6 and IL-8 in a dose-dependent manner.

COX-2, a pro-inflammatory mediator, promotes a number of inflammatory factors in numerous cells and tissues (26). Tsutakawa et al (27) demonstrated upregulation of COX-2 mRNA expression in rat skin undergoing ischemia/reperfusion (I/R) lesions, and that NS-398, an inhibitor of COX-2, abrogates nicotine induced-skin necrosis and apoptosis resulting from I/R. The present study indicated that AS-IV reduced the protein expression levels of COX-1, COX-2, HMGB1 and ICAM-1, suggesting inhibitory effects of AS-IV on the production of inflammatory mediators and molecules. Furthermore, in RA rat models induced by collagen, a daily dose of $500 \mathrm{mg} / \mathrm{kg}$ of type II collagen significantly increased IL- $1 \beta$, TNF- $\alpha$, IL- 6 and IL- 8 production, and the protein expression of COX-2 and iNOS, whereas treatment of AS-IV had a negative effect on the productions of these inflammatory mediators and genes.

$\mathrm{NF}-\mathrm{\kappa B}$ has an important role in regulating the expression of numerous genes involved in inflammatory responses, including the cytokines IL- $1 \beta$ and TNF- $\alpha$, and the chemokines CXCL5, CCL5, matrix metalloproteinase-1 (MMP-1) and MMP-3, which are associated with the development and progression of RA $(28,29)$. The production of these mediators contributes to the enhancement of inflammatory reactions leading to further activation of NF- $\kappa \mathrm{B}$. This continuous $\mathrm{NF}-\kappa \mathrm{B}$ activation has been observed in human and animal models of RA (30). In the present study, the western blot assays demonstrated that AS-IV suppressed NF- $\kappa$ B activation in the LPS-stimulated synoviocytes and RA rat models in a dose-dependent manner.

The transcriptional activity of NF- $\mathrm{kB}$ is regulated in the nucleus by three mitogen-activated protein kinase (MAPK) pathways, including p42/p44 MAPK, p38 MAPK and JNK, all of which has been reported to be activated by HMGB1 (31). Concomitant with activation of the NF- $\mathrm{kB}$ pathway, HMGB1 results in phosphorylation of extracellular signal-related kinase and MMP expression (32). HMGB1 promotes protein 
kinase B phosphorylation via IL-1 $\beta$, a signaling pathway associated with fibroblast survival and proliferation in the RA synovium (33). Therefore, a foundation is provided to communicate with other signaling pathways via an additional level of regulation. Based on this, the present study investigated whether AS-IV had an effect on the MAPK pathways in addition to the activation of $\mathrm{NF}-\kappa \mathrm{B}$. The results of the current study demonstrated that HMGB1-stimulated p38 and JNK1/2 activation were attenuated by AS-IV treatment. Thus, p38 and JNK1/2 pathways may have mediated the suppressive effects of AS-IV.

Various targets are investigated for the development of novel agents for RA therapy, including pro-inflammatory mediators, MMPs and osteoclastogenesis. The NF- $\mathrm{B}$ pathway regulates numerous target molecules and acts as an effective therapeutic target. The results of the present study demonstrated that AS-IV significantly reduced the severity of inflammation in the LPS-stimulated synoviocytes and in the collagen-induced RA rats via inhibition of the HMGB1-dependent JNK1/2- and p38-activated NF- $\mathrm{B} / \mathrm{COX}-2$ pathway. In conclusion, the current study suggests that AS-IV may be used as a therapeutic agent for the treatment of inflammatory responses in arthritis.

\section{Acknowledgements}

The current study was supported by the National Natural Science Foundation of China (grant no. NSFC 81272056).

\section{References}

1. Davignon JL, Hayder M, Baron M, Boyer JF, Constantin A, Apparailly F, Poupot $\mathrm{R}$ and Cantagrel A: Targeting monocytes/macrophages in the treatment of rheumatoid arthritis. Rheumatology (Oxford) 52: 590-598, 2013.

2. Walter GJ, Evans HG, Menon B, Gullick NJ, Kirkham BW, Cope AP, Geissmann F and Taams LS: Interaction with activated monocytes enhances cytokine expression and suppressive activity of human CD4 CD45RO CD25 CD127low regulatory T cells. Arthritis Rheum 65: 627-638, 2013.

3. Bianchi R, Giambanco I and Donato R: S100B/RAGE-dependent activation of microglia via NF- $\kappa \mathrm{B}$ and AP-1: Co-regulation of COX-2 expression by S100B, IL-1 $\beta$ and TNF- $\alpha$. Neurobiol Aging 31: 665-677, 2010

4. Salminen A, Huuskonen J, Ojala J, Kauppinen A, Kaarniranta K and Suuronen T: Activation of innate immunity system during aging: NF- $\mathrm{KB}$ signaling is the molecular culprit of inflamm-aging. Ageing Res Rev 7: 83-105, 2008.

5. Sheeba M and Asha V: Cardiospermum halicacabum ethanol extract inhibits LPS induced COX-2, TNF- $\alpha$ and iNOS expression, which is mediated by $\mathrm{NF}-\kappa \mathrm{B}$ regulation, in RAW264.7 cells. J Ethnopharmacol 124: 39-44, 2009.

6. Kumar S, Singhal V, Roshan R, Sharma A, Rembhotkar GW and Ghosh B: Piperine inhibits TNF- $\alpha$ induced adhesion of neutrophils to endothelial monolayer through suppression of

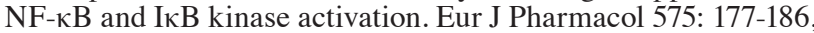
2007.

7. Wang B: Anti-arthritic effect of astragaloside IV and its molecular mechanism. ICS 1, 2014 (Review).

8. Ma XQ, Shi Q, Duan J, Dong TT and Tsim KW: Chemical analysis of Radix Astragali (Huangqi) in China: A comparison with its adulterants and seasonal variations. J Agric Food Chem 50: 4861-4866, 2002.

9. Lei H, Wang B, Li WP, Yang Y, Zhou AW and Chen MZ: Anti-aging effect of astragalosides and its mechanism of action. Acta Pharmacol Sin 24: 230-234, 2003.

10. Yu QT, Qi LW, Li P, Yi L, Zhao J and Bi Z: Determination of seventeen main flavonoids and saponins in the medicinal plant Huang-qi (Radix Astragali) by HPLC-DAD-ELSD. J Sep Sci 30: 1292-1299, 2007.
11. Cho WCS and Leung KN: In vitro and in vivo immunomodulating and immunorestorative effects of Astragalus membranaceus. J Ethnopharmacol 113: 132-141, 2007.

12. Chan WS, Durairajan SSK, Lu JH, Wang Y, Xie LX, Kum WF, Koo I, Yung KKL and Li M: Neuroprotective effects of Astragaloside IV in 6-hydroxydopamine-treated primary nigral cell culture. Neurochem Int 55: 414-422, 2009.

13. Zhang WD, Chen H, Zhang C, Liu RH, Li HL and Chen HZ: Astragaloside IV from Astragalus membranaceus shows cardioprotection during myocardial ischemia in vivo and in vitro. Planta Med 72: 4-8, 2006.

14. Nagy G, Koncz A, Telarico T, Fernandez D, Érsek B, Buzás E and Perl A: Central role of nitric oxide in the pathogenesis of rheumatoid arthritis and sysemic lupus erythematosus. Arthritis Res Ther 12: 210, 2010.

15. Schett G, Coates LC, Ash ZR, Finzel S and Conaghan PG: Structural damage in rheumatoid arthritis, psoriatic arthritis, and ankylosing spondylitis: Traditional views, novel insights gained from TNF blockade, and concepts for the future. Arthritis Res Ther 13: S4, 2011.

16. Wang B and Chen MZ: Astragaloside IV possesses antiarthritic effect by preventing interleukin $1 \beta$-induced joint inflammation and cartilage damage. Arch Pharm Res 37: 793-802, 2014.

17. Zhu L, Wei W, Zheng YQ and Jia XY: Effects and mechanisms of total glucosides of paeony on joint damage in rat collagen-induced arthritis. Inflamm Res 54: 211-220, 2005.

18. McInnes IB and Schett G: The pathogenesis of rheumatoid arthritis. N Engl J Med 365: 2205-2219, 2011.

19. Takaishi S, Okumura T, Tu S, Wang SSW, Shibata W, Vigneshwaran R, Gordon SAK, Shimada Y and Wang TC: Identification of gastric cancer stem cells using the cell surface marker CD44. Stem Cells 27: 1006-1020, 2009.

20. Lee Y, Hwang J, Lee H, Cheon YJ, Ryu JH, Lee SI, Kwak HB, Lee SM, Kim JS, Park JW, et al: SPA0355, a thiourea analogue, inhibits inflammatory responses and joint destruction in fibroblast-like synoviocytes and mice with collagen-induced arthritis. Br J Pharmacol 164: 794-806, 2011.

21. Han I, Jeong SJ, Lee HJ, Koh W, Lee HJ, Lee EO, Kim HS, Lee SJ, Chen CY, Jung MH and Kim SH: Proteomic analysis of mesenchymal stem-like cells derived from ovarian teratoma: Potential role of glutathione S-transferase M2 in ovarian teratoma. Proteomics 11: 352-360, 2011.

22. Paramalingam S S, Thumboo J, Vasoo S, Thio S T, Tse C and Fong K-Y. In vivo pro-and anti-inflammatory cytokines in normal and patients with rheumatoid arthritis. Ann Acad Med Singap 36:96, 2007.

23. Katchamart W, Trudeau J, Phumethum V and Bombardier C: The efficacy and toxicity of methotrexate (MTX) monotherapy versus MTX combination therapy with non-biological disease-modifying anti-rheumatic drugs in rheumatoid arthritis: A systematic review and meta-analysis. Ann Rheum Dis 68: 1105-1112, 2009.

24. Simon L and Yocum D: New and future drug therapies for rheumatoid arthritis. Rheumatology (Oxford) 39 (Suppl 1): 36-42, 2000.

25. Xin W, Huang C, Zhang X, Xin S, Zhou Y, Ma X, Zhang D, Li Y, Zhou S, Zhang D, et al: Methyl salicylate lactoside inhibits inflammatory response of fibroblast-like synoviocytes and joint destruction in collagen-induced arthritis in mice. Br J Pharmacol 171: 3526-3538, 2014.

26. Yang C, Yang Z, Zhang M, Dong Q, Wang X, Lan A, Zeng F, Chen $\mathrm{P}$, Wang $\mathrm{C}$ and Feng J. Hydrogen sulfide protects against chemical hypoxia-induced cytotoxicity and inflammation in $\mathrm{HaCaT}$ cells through inhibition of $\mathrm{ROS} / \mathrm{NF}-\kappa \mathrm{B} / \mathrm{COX}-2$ pathway. PLoS One 6:e21971, 2011.

27. Tsutakawa S, Kobayashi D, Kusama M, Moriya T and Nakahata N: Nicotine enhances skin necrosis and expression of inflammatory mediators in a rat pressure ulcer model. Br J Dermatol 161: 1020-1027, 2009.

28. Ha MK, Song YH, Jeong SJ, Lee HJ, Jung JH, Kim B, Song HS, Huh JE and Kim SH: Emodin inhibits proinflammatory responses and inactivates histone deacetylase 1 in hypoxic rheumatoid synoviocytes. Biol Pharm Bull 34: 1432-1437, 2011.

29. Peng C, Perera PK, Li YM, Fang WR, Liu LF and Li FW: Anti-inflammatory effects of Clematis chinensis Osbeck extract (AR-6) may be associated with NF- $\kappa \mathrm{B}, \mathrm{TNF}-\alpha$, and COX-2 in collagen-induced arthritis in rat. Rheumatol Int 32: 3119-3125, 2012 . 
30. Hah YS, Lee YR, Jun JS, Lim H-S, Kim HO, Jeong YG, Hur GM, Lee SY, Chung MJ, Park JW, et al: A20 suppresses inflammatory responses and bone destruction in human fibroblast-like synoviocytes and in mice with collagen-induced arthritis. Arthritis Rheum 62: 2313-2321, 2010.

31. García-Arnandis I, Guillén MI, Gomar F, Pelletier JP, Martel-Pelletier J and Alcaraz MJ: High mobility group box 1 potentiates the pro-inflammatory effects of interleukin-1 $\beta$ in osteoarthritic synoviocytes. Arthritis Res Ther 12: R165, 2010.
32. Loeser RF, Yammani RR, Carlson CS, Chen H, Cole A, Im HJ, Bursch LS and Yan SD: Articular chondrocytes express the receptor for advanced glycation end products: Potential role in osteoarthritis. Arthritis Rheum 52: 2376-2385, 2005.

33. Zhang HG, Wang Y, Xie JF, Liang X, Liu D, Yang P, Hsu HC, Ray RB and Mountz JD: Regulation of tumor necrosis factor alpha-mediated apoptosis of rheumatoid arthritis synovial fibroblasts by the protein kinase Akt. Arthritis Rheum 44: 1555-1567, 2001. 